\title{
CRAQUEAMENTO TERMO-CATALÍTICO DA MISTURA ÓLEO DE FRITURA USADO-LODO DE ESTAMPARIA TÊXTIL PARA A PRODUÇÃO DE ÓLEO COM BAIXO ÍNDICE DE ACIDEZ
}

\author{
Vanderléia Botton \\ Departamento de Química, Universidade Federal do Paraná, CP 19081, 81530-900 Curitiba - PR, Brasil \\ Dilamara Riva e Edesio Luiz Simionatto \\ Instituto de Pesquisas Tecnólógicas de Blumenau, Fundação Universidade Regional de Blumenau, 89030-000 Blumenau - SC, Brasil \\ Vinicyus Rodolfo Wiggers, Laércio Ender, Henry França Meier e António André Chivanga Barros* \\ Departamento de Engenharia Química, Fundação Universidade Regional de Blumenau, 89030-000 Blumenau - SC, Brasil
}

Recebido em 29/3/2011; aceito em 3/11/11; publicado na web 13/1/12

\begin{abstract}
THERMO-CATALYTIC CRACKING OF THE MIXTURE OF USED FRYING OIL - TEXTILE STAMPING SLUDGE FOR THE PRODUCTION OF OIL WITH LOW ACIDITY INDEX. In this work, cracking experiments were performed to carry out the thermal conversion of the mixture of used frying oil and textile stamping sludge in continuous reactor. The textile stamping sludge was used to catalyze the reaction of thermal cracking. The physical and chemical properties of the oil produced were analyzed. Among the results of this analysis the level of acidity in the range of $12 \mathrm{mg} \mathrm{KOH} / \mathrm{g}$ stands out. Low levels of acidity as this particular mean better quality oil. In this regard it is important that further researches on processes of conversion of residual oil occur.
\end{abstract}

Keywords: used frying oil; sludge textile stamping; thermo-catalytic cracking.

\section{INTRODUÇÃO}

As gorduras, os óleos e os resíduos gordurosos são potenciais fontes de produção de biocombustíveis capazes de substituírem os combustíveis fósseis. ${ }^{1}$ Os óleos vegetais e as gorduras animais são triglicerídeos de ácidos graxos variados, encontrados na forma sólida ou líquida. ${ }^{2}$ Eles são geralmente dispostos inadequadamente na rede de esgoto, provocando problemas de entupimento de tubulações e aumentando o custo operacional nas estações de tratamento de esgoto. Atualmente, a reciclagem de resíduos de frituras ganha projeção no Brasil, dado o seu poder energético e a possibilidade de sua reutilização como carga oleosa na produção de tintas, base lipídica na produção de rações animais e em vários outros processos industriais. As pesquisas ${ }^{3,4}$ mostram que as massas de resíduos gordurosos produzidas são significativas. Estes resíduos gordurosos, quando utilizados como biomassa nos processos de termoconversão para produção de biocombustíveis e precursores químicos, podem substituir substancialmente a matéria-prima proveniente de fontes fósseis.

Neste contexto, a literatura aponta o craqueamento térmico ${ }^{5}$ e o craqueamento termo-catalítico como processos com capacidade para valorar os resíduos. Trabalhos recentemente publicados abordam temas voltados ao craqueamento térmico de resíduos sólidos, ${ }^{6-8}$ lodo de esgoto, ${ }^{9-15}$ resíduos gordurosos, ${ }^{16-19}$ resíduos têxteis ${ }^{20}$ e borra de tinta, ${ }^{21}$ mostrando a relevância científica e tecnológica destes processos.

Os processos de termoconversão são promissores, pois utilizam tecnologias semelhantes à do refino das frações pesadas do petróleo para produção de gasolina e diesel. ${ }^{16}$ Com a implementação do craqueamento térmico de óleos vegetais, podem-se obter misturas de hidrocarbonetos, similares às do petróleo, com a incorporação de compostos oxigenados. ${ }^{22} \mathrm{~A}$ qualidade e a proporção dos produtos do craqueamento dependem de diversos fatores, como a composição química da matéria-prima utilizada, a temperatura do processo, o tempo de residência e, também, a presença de catalisadores. ${ }^{1,23}$

O óleo derivado do craqueamento térmico de óleo de tungue pode ser utilizado in natura como biocombustível, ou ser refinado para a

*e-mail: chivanga_barros@furb.br produção de biocombustíveis com características similares ao diesel, à gasolina e ao querosene. ${ }^{24}$ Com o uso da destilação dos produtos obtidos por craqueamento térmico é possível obter biocombustíveis com os parâmetros físico-químicos similares ao óleo diesel. ${ }^{1}$ Entre alguns autores existem opiniões contraditórias sobre o uso do produto craqueado direto nos motores devido, também, ao elevado índice de acidez, que é visto como umas das desvantagens do óleo derivado do craqueamento térmico. O elevado índice de acidez no produto formado é devido à presença de ácidos graxos e carboxílicos de cadeia curta. ${ }^{17,25,26}$ Neste contexto, demanda-se o uso de catalisadores e implementação de condições operacionais adequadas para garantir a redução do teor de ácidos para os níveis aceitáveis de qualidade destes biocombustíveis.

Este trabalho teve como objetivo realizar ensaios experimentais de craqueamento térmico da mistura de óleo de fritura e lodo de estamparia têxtil, em um reator contínuo e em escala de bancada. Foi avaliada a qualidade dos biocombustíveis produzidos, considerando-se que o lodo de estamparia têxtil é composto, essencialmente, por óxidos metálicos que atuam como catalisadores. A presença dos compostos inorgânicos no processo de craqueamento minimiza o teor de ácidos graxos e carboxílicos nos produtos da reação química.

\section{PARTE EXPERIMENTAL}

Para o desenvolvimento deste trabalho foi utilizado óleo de fritura usado oriundo de estabelecimentos comerciais e lodo têxtil proveniente da atividade de estamparia. A amostra de lodo foi caracterizada com a avaliação do teor de sólidos totais voláteis (ABNT NBR 14363), ${ }^{27}$ teor de cinzas (ABNT NBR 9382), ${ }^{28}$ teor de umidade, massa específica (ABNT NBR 6457) ${ }^{29}$ e medida do $\mathrm{pH}$ utilizando-se um pHmetro Digimed, série 24177. A umidade das amostras de lodo foi ajustada para $80 \%$ com água destilada, e de óleo de fritura usado foram misturadas e homogeneizadas manualmente para a composição de uma amostra padrão, na proporção mássica de 1:1 (m/m).

$\mathrm{O}$ aparato experimental, em escala de bancada, utilizado para a condução dos experimentos de craqueamento termo-catalítico é apresentado na Figura 1. Este aparato é composto pelas seguintes 
seções: 1) seção de alimentação que contém um reservatório e uma bomba dosadora que opera em vazão constante; 2) seção reacional que incorpora um reator tubular horizontal dotado de uma rosca transportadora e resistências elétricas; 3) tanque de expansão para coleta de materiais sólidos; 4) sistema de condensação equipado com um trocador de calor; 5) tanque flash para coleta dos condensáveis; 6) seção para coleta dos gases não condensáveis; 7) sistema de controle e aquisição de dados.

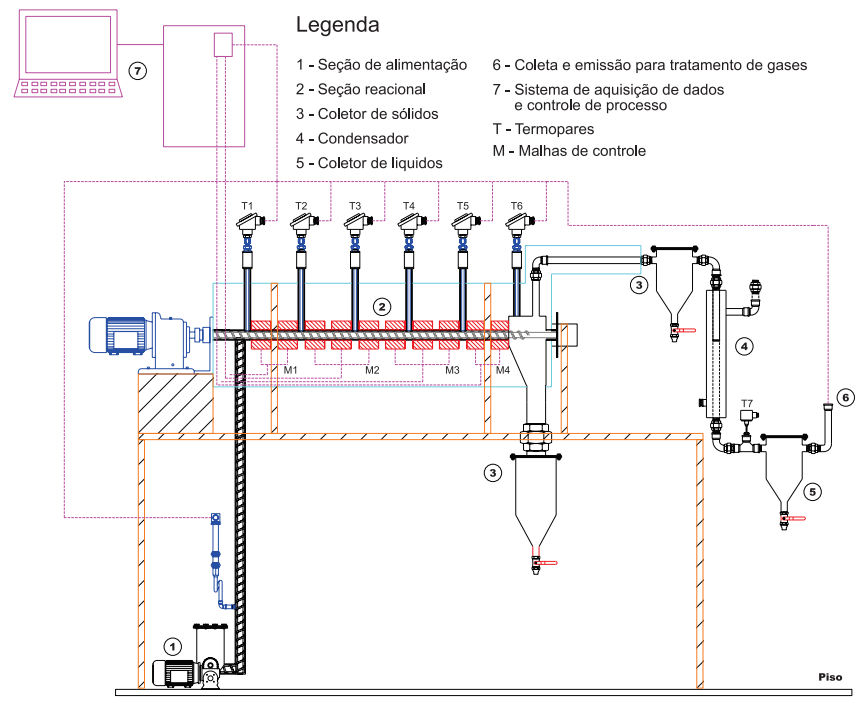

Figura 1. Aparato experimental utilizado

O reator contém 6 sensores de temperatura do tipo "K" para aferição das temperaturas na entrada, saída e ao longo do reator, um PT 100 (T7) para medida da temperatura do condensado e um sensor para monitorar a pressão no reator. A seção reacional contém resistências elétricas para o aquecimento da unidade e foi divida em 4 malhas de controle distintas, com o intuito de favorecer a isotermicidade do sistema. A primeira malha (M1) é responsável pela secagem do material e é composta por 2 resistências elétricas (abraçadeira em cerâmica) de $350 \mathrm{~W}$ cada; a segunda malha (M2) está localizada na região de volatilização com 3 resistências de $350 \mathrm{~W}$ cada; a terceira malha (M3) com 3 resistências de $350 \mathrm{~W}$ cada e a quarta seção (M4) com 2 resistências de $350 \mathrm{~W}$ cada e que constituem a seção reacional da unidade. Devido à demanda por altas temperaturas que promovem a quebra das cadeias carbônicas, o reator é termicamente isolado com manta de fibra cerâmica para evitar a perda de calor para o ambiente e garantir a segurança de operação, em condições isotérmicas.

A unidade contém um sistema SCADA (Software Control and Data Aquisition) dotado de um controlador lógico programável (CP1000) e um software (Workbench Softllution) que possibilita a manutenção das condições operacionais através do controle das variáveis manipuladas e aquisição de dados de todas as variáveis do processo aferidas durante o experimento.

\section{Procedimento experimental}

Empregou-se o planejamento fatorial $\left(2^{2}\right)$ que considera como variável dependente o rendimento da fase orgânica da reação (óleo derivado do craqueamento) e, como variáveis independentes, o tempo de residência e a temperatura de operação. Realizou-se um experimento adicional para verificar as condições intermediárias (ponto central). O tempo de residência do processo contínuo foi controlado através da alteração da vazão mássica de alimentação, mediante variação da frequência do motor da bomba de alimentação. Para cada experimento do planejamento utilizou-se $1 \mathrm{~kg}$ de amostra padrão, independen- temente da respectiva taxa mássica. $\mathrm{O}$ rendimento do processo de craqueamento termo-catalítico dos experimentos foi determinado por pesagem da massa de óleo derivado do craqueamento produzido durante toda a operação do craqueamento de $1 \mathrm{~kg}$ da amostra padrão adicionada no reservatório de matéria-prima do sistema reacional. O balanço macroscópico de massa permite relacionar a corrente de entrada do resíduo com as correntes de saída da fase líquida, da fase sólida e da fase gasosa, considerando que o sistema, na sua globalidade, opera em estado estacionário e mistura perfeita.

Foi realizado um experimento de craqueamento do óleo de fritura usado sem a presença do lodo de estamparia têxtil, com o objetivo de se comparar os resultados obtidos com as análises de índice de acidez e densidade das fases leve e pesada dos óleos obtidos do craqueamento do óleo de fritura usado com e sem o lodo de estamparia têxtil.

O óleo foi fracionado por destilação simples, que resultou na obtenção de duas fases: uma leve e outra pesada. Estas fases foram comparadas com a gasolina $\mathrm{C}$ (padrão nacional) e com o diesel, respectivamente. A comparação foi feita mediante execução de experimentos de curva de destilação, de acordo com a ABNT NBR $9619,{ }^{30}$ análise cromatográfica, densidade relativa e índice de acidez. Os ensaios de destilação, de acordo com a norma, relacionam a temperatura de ebulição com a composição, as propriedades e o comportamento do combustível e a volatilidade como parâmetro de maior relevância nesta análise, e possibilitam uma análise da qualidade do biocombustível. ${ }^{31}$

Realizaram-se experimentos de destilação simples para o corte do óleo, por faixas de temperatura de ebulição. Para obtenção da fase leve, utilizou-se a faixa de temperatura de $30-180{ }^{\circ} \mathrm{C}$ e para a fase pesada os produtos foram obtidos com temperaturas acima de $180^{\circ} \mathrm{C}$.

Para a análise cromatográfica utilizou-se um cromatógrafo gasoso marca Shimadzu, com amostrador automático AOC - 5000. A coluna utilizada foi a RTX1 (30,00 m x 0,32 mm d.i. e filme com 3,00 $\mu \mathrm{m}$ de espessura) e injeção com vazão de $1,20 \mathrm{~mL} \mathrm{~min}^{-1}$ e velocidade linear de $27 \mathrm{~cm} \mathrm{~s}^{-1}$. Temperatura de operação de $150^{\circ} \mathrm{C}$ durante o primeiro min, com incremento de $5^{\circ} \mathrm{C} \mathrm{min}{ }^{-1}$ até $280^{\circ} \mathrm{C}$, estabilizando-se assim por $23 \mathrm{~min}$. O tempo total do ensaio cromatográfico foi de $50 \mathrm{~min}$. A temperatura do detector de ionização de chama (DIC) foi de 280 ${ }^{\circ} \mathrm{C}$ e a temperatura do injetor de $250^{\circ} \mathrm{C}$, utilizando-se hélio como gás de arraste.

A densidade relativa definida como a relação entre a massa específica do produto a $20^{\circ} \mathrm{C}$ e a massa específica da água a $4{ }^{\circ} \mathrm{C}$ foi determinada utilizando-se o método do densímetro. ${ }^{32}$

O índice de acidez fornece dados sobre a concentração de ácidos graxos e carboxílicos de cadeia curta remanescentes nos produtos e é definido como a massa em mg de hidróxido de potássio necessário para neutralizar $1 \mathrm{~g}$ da amostra. Esta análise foi realizada seguindo as condições estabelecidas pela ASTM D $974 .{ }^{33}$

O rendimento dos produtos do craqueamento termo-catalítico foi calculado com base na Equação 1:

$$
\% \text { Rend }=\frac{M_{\text {Produto }}}{M_{\text {Residuos }}} .100
$$

\section{RESULTADOS E DISCUSSÃO}

\section{Caracterização do lodo de estamparia têxtil}

Os dados obtidos possibilitaram caracterizar a amostra padrão de lodo e evidenciaram o caráter alcalino com pH 8,8 $\pm 1,0$ atribuído à presença dos produtos de limpeza dos quadros, produtos compostos majoritariamente por $\mathrm{NaOH}$, tendo como massa específica do lodo úmido $1100,0 \mathrm{~kg} \mathrm{~m}^{-3} \pm 1,4$, lodo seco $422,0 \mathrm{~kg} \mathrm{~m}^{-3} \pm 2,0$, umidade ca. $72,07 \%$, teor de sólidos totais voláteis $51,94 \% \pm 1,7$ e teor de 
cinzas $45,46 \% \pm 0,5$. O óleo de fritura usado foi caracterizado antes do processo de craqueamento termo-catalítico e apresentou índice de acidez de 1,55 $\pm 0,42$.

\section{Desempenho do processo de craqueamento termo-catalítico}

Para cada experimento procedeu-se o fechamento do balanço macroscópico de massa para avaliar o desempenho do processo, principalmente quanto ao rendimento em fase orgânica dos produtos líquidos. O desempenho do processo para os experimentos executados está apresentado na Tabela 1.

Com relação à fase orgânica $\left(\mathrm{m}_{\mathrm{o}}\right)$, Tabela 1 , observa-se que os resultados dos experimentos realizados à temperatura de $525{ }^{\circ} \mathrm{C}$ são influenciados pelo tempo de residência. Os experimentos com maior tempo de residência ( 2 e 4 ) proporcionam menor massa da fase orgânica, como resultado do deslocamento das reações de craqueamento em direção aos compostos com cadeia carbônica curta, não condensáveis, que aumentam o rendimento da fase gasosa. A comparação entre os resultados dos experimentos 1 e 3 realizados, respectivamente, a 525 e $475^{\circ} \mathrm{C}$, com o mesmo tempo de residência, mostra que o incremento da temperatura do processo proporciona menor massa da fase orgânica $\left(\mathrm{m}_{\mathrm{o}}\right)$, conforme esperado.

O rendimento médio de cada experimento é maior para os experimentos 1, 3 e 5 quando a análise é feita com base na fração orgânica. Este comportamento está associado diretamente ao menor tempo de residência, com consequente redução das frações da fase gasosa e incremento no rendimento da fase orgânica.

\section{Curvas de destilação do óleo derivado do craqueamento}

Os produtos líquidos do processo foram coletados, decantados e armazenados, sendo a fase aquosa descartada e a fase orgânica (óleo derivado do craqueamento) destilada. O óleo derivado do craqueamento foi caracterizado mediante determinação da curva de destilação e análise cromatográfica para determinar a composição na cadeia de hidrocarbonetos leves e pesados, em função do número de carbonos. A Figura 2 apresenta as curvas de destilação, da fase orgânica, obtidas no processo de craqueamento termo-catalítico dos experimentos 1, 2, 3, 4 e 5 e das suas réplicas, das gasolinas A (sem etanol) e C(com etanol), e do diesel. Com as curvas de destilação pode-se observar o comportamento termodinâmico do fracionamento do óleo derivado do craqueamento termo-catalítico de óleo de fritura usado. Pode-se, por outro lado, estabelecer a relação entre a temperatura de ebulição dos componentes presentes na fase orgânica e o volume do condensado e coletado. ${ }^{34}$ Pela análise das curvas de destilação do óleo (Figuras $2 \mathrm{a}$ e $2 \mathrm{~b}$ ) verificam-se características semelhantes às das curvas de destilação do diesel. As gasolinas $\mathrm{A}$ e $\mathrm{C}$ apresentam hidrocarbonetos na faixa de $\mathrm{C}_{4^{-}}$ $\mathrm{C}_{12}$, portanto, compostos com ponto de ebulição menores que os principais constituintes do óleo. ${ }^{35}$

Na Figura 2a observa-se o aumento acentuado da temperatura
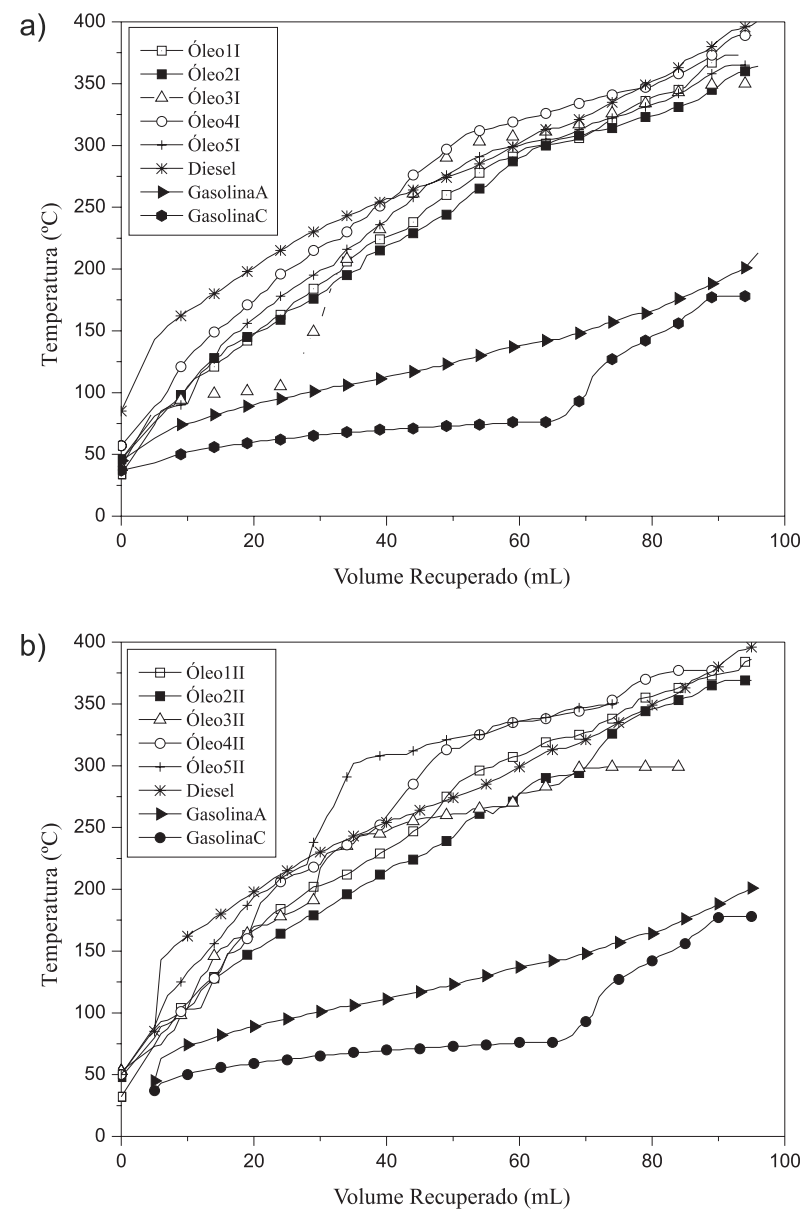

Figura 2. Curvas de destilação da fase orgânica dos experimentos 1, 2, 3, 4 e 5 (I), gasolina A e C e diesel (a) e da réplica dos experimentos 1, 2, 3, 4 e 5 (II), gasolina A e C e diesel (b)

de ebulição com o volume, principalmente para o experimento 4, realizado a $475^{\circ} \mathrm{C}$ e vazão mássica de $0,26 \mathrm{~kg} \mathrm{~h}^{-1}$. Isto ocorre, provavelmente, por concentrar frações de hidrocarbonetos com maior número de carbonos. A comparação destes resultados com os do experimento 3 , realizado com vazão mássica de $0,50 \mathrm{~kg} \mathrm{~h}^{-1} \mathrm{e}$ na mesma temperatura, mostra a influência do tempo de residência sobre o teor de hidrocarbonetos leves. Os resultados do experimento 3 indicam menores temperaturas de ebulição, portanto, maior concentração de componentes leves se comparado com o experimento 4 .

A análise das curvas de destilação do experimento 1 , realizado a $525^{\circ} \mathrm{C}$ e vazão mássica de $0,50 \mathrm{~kg} \mathrm{~h}^{-1}$, comparada com as do experimento 2, realizado na mesma temperatura e vazão mássica de $0,26 \mathrm{~kg} \mathrm{~h}^{-1}$, permite observar que o tempo de residência influencia na qualidade dos produtos obtidos. Nesta análise observa-se que a curva do experimento 2 apresenta menores temperaturas de ebulição, se comparado com o experimento 1 .

Tabela 1. Resultados médios dos balanços de massa dos experimentos de craqueamento termo-catalítico

\begin{tabular}{|c|c|c|c|c|c|c|}
\hline Experimento & $\mathrm{T}\left({ }^{\circ} \mathrm{C}\right) / \mathrm{F}\left(\mathrm{kg} \mathrm{h}^{-1}\right)^{1}$ & $\mathrm{~m}_{\mathrm{R}}^{2}(\mathrm{~kg})$ & $\mathrm{m}_{\mathrm{s}}^{3}(\mathrm{~kg})$ & $\mathrm{m}_{\mathrm{O}}^{4}(\mathrm{~kg})$ & $\mathrm{m}_{\mathrm{A}}^{5}(\mathrm{~kg})$ & $\mathrm{m}_{\text {Gás }}{ }^{6}(\mathrm{~kg})$ \\
\hline 1 & $525 / 0,50$ & 1,000 & $0,174 \pm 2,0$ & $0,240 \pm 2,8$ & $0,310 \pm 7,1$ & $0,271 \pm 0,8$ \\
\hline 2 & $525 / 0,26$ & 1,000 & $0,179 \pm 2,1$ & $0,190 \pm 4,3$ & $0,270 \pm 1,4$ & $0,361 \pm 4,9$ \\
\hline 3 & $475 / 0,50$ & 1,000 & $0,220 \pm 5,7$ & $0,260 \pm 2,8$ & $0,240 \pm 8,5$ & $0,280 \pm 11,3$ \\
\hline 4 & $474 / 0,26$ & 1,000 & $0,225 \pm 1,8$ & $0,220 \pm 4,3$ & $0,210 \pm 1,4$ & $0,345 \pm 0,4$ \\
\hline 5 & $500 / 0,35$ & 1,000 & $0,202 \pm 0,1$ & $0,260 \pm 2,2$ & $0,270 \pm 4,2$ & $0,269 \pm 1,5$ \\
\hline
\end{tabular}

(1) T é temperatura de operação e F é a vazão mássica de alimentação dos experimentos; (2) Massa de resíduos inicial; (3) Massa de produto sólido; (4) massa de produto orgânico (óleo); (5) Massa de produto aquoso; (6) Massa de produto gasoso. 


\section{Análise cromatográfica do óleo derivado do craqueamento}

A análise cromatográfica foi utilizada para avaliar o teor de hidrocarbonetos presentes na amostra de óleo derivado do craqueamento, em termos de número de carbonos. Observou-se que o percentual de carbonos na faixa de $\mathrm{C}_{4} \mathrm{a} \mathrm{C}_{10}$ representa índices mais expressivos para os experimentos 1,2 e 3 que atingem patamares de 46,47 e $54 \%$, respectivamente. A faixa de carbonos $\mathrm{C}_{4}$ a $\mathrm{C}_{10}$ constitui-se no principal referencial da gasolina e representa hidrocarbonetos com teores de carbonos com característica de combustíveis mais leves, de maior volatilidade e menores temperaturas de ebulição.

Na comparação entre os dados dos experimentos 1 e 2 realizados a $525^{\circ} \mathrm{C}$ e vazões mássicas de 0,50 e $0,26 \mathrm{~kg} \mathrm{~h}^{-1}$, respectivamente, observa-se que o número de compostos na faixa de $\mathrm{C}_{4}$ a $\mathrm{C}_{10}$ é maior para o experimento 2 . Os experimentos 3 e 4 realizados na mesma temperatura, $475^{\circ} \mathrm{C}$, vazões mássicas de 0,26 e $0,50 \mathrm{~kg} \mathrm{~h}^{-1}$, respectivamente, e as réplicas destes experimentos, 3 (II) e 4 (II), apresentam comportamento similar aos resultados dos experimentos 1 e 2 .

O experimento 2 apresenta maior concentração de hidrocarbonetos com $\mathrm{C}_{11}$ até $\mathrm{C}_{26}$, se comparado com os resultados obtidos do experimento 1. É possível concluir que o tempo de residência influencia diretamente na distribuição das frações destes componentes na fase orgânica. $\mathrm{O}$ incremento do tempo de residência favorece a quebra das cadeias carbônicas em moléculas menores.

A caracterização da fase orgânica da duplicata dos experimentos, por análise cromatográfica, mostra que os experimentos 3 e 4 , realizados a $475^{\circ} \mathrm{C}$ e vazões mássicas de 0,50 e $0,26 \mathrm{~kg} \mathrm{~h}^{-1}$, respectivamente, são similares aos experimentos 1 e 2 com relação à distribuição do número de carbonos. Por outro lado, a maior fração de hidrocarbonetos com número de carbonos entre $\mathrm{C}_{4} \mathrm{e}_{10}$ é obtida nos experimentos 4 e 5 , realizados com vazões mássicas de $0,26 \mathrm{~kg} \mathrm{~h}^{-1}$ e, portanto, com os maiores tempos de residência. Os hidrocarbonetos com número de carbonos maiores que $\mathrm{C}_{10}$, distribuem-se em menores percentuais nas amostras da fase orgânica dos experimentos 3 e 4, todos com percentuais similares. A vazão mássica de alimentação utilizada em cada experimento proporciona tempos de operação diferentes, o que evidencia a oscilação de frações de hidrocarbonetos com carbonos entre $\mathrm{C}_{12}$ e $\mathrm{C}_{26}$.

Pode-se concluir que o efeito da temperatura tem menor influência no processo se comparado com o tempo de residência. Esta afirmação sugere que a atividade catalítica dos óxidos metálicos presentes no lodo de estamparia se sobrepõe ao efeito da temperatura nas reações de craqueamento e que afeta a distribuição dos compostos com diferentes números de carbonos no óleo derivado do craqueamento.

\section{Fracionamento do óleo derivado do craqueamento}

A fase orgânica dos experimentos foi destilada para separar misturas com diferentes pontos de ebulição. A fração vaporizada foi enriquecida nos componentes mais voláteis, enquanto que a fração líquida foi enriquecida nos compostos menos voláteis e, portanto, com cadeias carbônicas maiores e de maiores temperaturas de ebulição. ${ }^{36}$ O fracionamento possibilita quantificar e avaliar o rendimento do óleo derivado do craqueamento dos experimentos realizados, com relação às fases leve (similar à gasolina) e pesada (similar ao diesel). A purificação por destilação fracionada resultou na formação de duas fases, sendo a fase inferior separada por decantação. Com o fechamento dos balanços de massa da destilação do óleo, avaliaram-se os resultados obtidos e os dados foram comparados entre si. A massa de óleo de cada experimento é o resultado da soma das frações da fase orgânica do experimento principal e da respectiva réplica.

Em termos de rendimento dos produtos obtidos por fracionamento do óleo, observa-se que o maior rendimento com relação à fase leve (30-180 ${ }^{\circ} \mathrm{C}$ ) foi proveniente do experimento $2(35,05 \%)$, seguido pelos experimentos 1 (32,86\%), 4 (21,96\%), 5 (20,68\%) e $3(18,87 \%)$. Para a fase pesada, obtida acima de $180^{\circ} \mathrm{C}$, constatou-se que o maior rendimento foi obtido do experimento 3 (70,95\%), seguido pelos experimentos 4 (59,84\%), 5 (I e II) $(54,85 \%), 1$ (I e II) $(52,64 \%)$ e 2 (I e II) $(50,93 \%)$, respectivamente. Na destilação de óleo derivado do craqueamento obtido a $525^{\circ} \mathrm{C}$, a partir de óleo residual de peixe, os autores deste artigo trabalharam na faixa de temperatura entre 30 e $220{ }^{\circ} \mathrm{C}$ e obtiveram rendimento, para a fase leve de $35,86 \%,{ }^{17}$ rendimento similar ao da fase leve do experimento 2, com 35,05\%, realizado também a $525^{\circ} \mathrm{C}$ e vazão mássica de $0,26 \mathrm{~kg} \mathrm{~h}^{-1}$. Para o mesmo experimento, o rendimento para a fase pesada $\left(150-400^{\circ} \mathrm{C}\right)$ foi de $34,83 \%,{ }^{17}$ abaixo do rendimento dos experimentos obtidos neste trabalho, principalmente quando comparado com a fase pesada do experimento 3, que apresentou rendimento de 70,95\%. Outro trabalho consistiu na destilação do óleo derivado do craqueamento produzido a partir de óleo de soja a $525^{\circ} \mathrm{C} .{ }^{18}$ Os autores fracionaram o óleo em duas fases, a fase leve obtida na faixa de $30-220^{\circ} \mathrm{C}$, que resultou no rendimento de 32 e $30 \%$ para os experimentos 5 e 6 , respectivamente. Para a fase pesada, avaliada na faixa de $150-400{ }^{\circ} \mathrm{C}$, o rendimento foi de $62 \%$ para os experimentos 5 e $6 .{ }^{18}$ Os resultados podem ser comparados com os experimentos 1 e 2 , para a fase leve, com rendimentos similares. Do craqueamento térmico de resíduos de pneus obteve-se rendimento da destilação da fase leve $\left(70-210{ }^{\circ} \mathrm{C}\right)$ de $30 \%,{ }^{37}$ percentuais inferiores aos rendimentos anteriormente descritos.

\section{Análise cromatográfica dos produtos do fracionamento do óleo}

Fez-se uma comparação dos resultados obtidos com a caracterização da fase leve e da gasolina. A fase leve do fracionamento com ponto de ebulição na faixa de 30 até $180{ }^{\circ} \mathrm{C}$ foi comparada com a gasolina $\mathrm{C}$, com cadeias carbônicas na faixa de $\mathrm{C}_{4} \mathrm{a} \mathrm{C}_{12}$. A caracterização por cromatografia foi realizada para determinar a distribuição de número de carbonos em cada uma das fases, resultantes da destilação fracionada do óleo derivado do craqueamento.

Na Figura 3, os dados das análises cromatográficas das fases leves dos experimentos foram comparados entre si, revelando que a distribuição de número de carbonos é acentuada na faixa de $\mathrm{C}_{4} \mathrm{a} \mathrm{C}_{10}$, comportamento similar ao da gasolina. Pode-se observar que a gasolina $\mathrm{C}$ concentra carbonos de $\mathrm{C}_{4} \mathrm{a} \mathrm{C}_{10}$ com um percentual de $97,68 \%$. A concentração dos compostos $\mathrm{C}_{4}-\mathrm{C}_{10}$ deve-se, em parte, à presença do etanol misturado à gasolina $\mathrm{C}$. Os resultados deste trabalho mostram que as fases leves, do experimento 3 , contêm um percentual maior de $\mathrm{C}_{4}-\mathrm{C}_{10}$ de $81,46 \%$, o experimento 4 com $71,51 \%$, o experimento 2 com $70,73 \%$, o experimento 5 com $69,37 \%$ e o experimento 1 com $67,19 \%$, respectivamente.

A Figura 3 b mostra a distribuição do número de carbonos da fase pesada do óleo derivado do craqueamento. Para os experimentos realizados a $525^{\circ} \mathrm{C}$ e vazões mássicas de 0,50 e $0,26 \mathrm{~kg} \mathrm{~h}^{-1}$, respectivamente, observam-se concentrações acentuadas de hidrocarbonetos na faixa de $\mathrm{C}_{4} \mathrm{a} \mathrm{C}_{10}$, com percentual de $12,6 \%$ para o experimento $1 \mathrm{e}$ $10 \%$ para o experimento 2 . A distribuição dos demais hidrocarbonetos é dispersa nas cadeias maiores, de $\mathrm{C}_{11}$ a $\mathrm{C}_{26}$. Perfil semelhante ao experimento 1 é observado no experimento 3 , experimentos executados com temperaturas de 525 e $475^{\circ} \mathrm{C}$, respectivamente, e vazão mássica de $0,50 \mathrm{~kg} \mathrm{~h}^{-1}$. As Figuras $3 \mathrm{a}$ e $3 \mathrm{~b}$ mostram a distribuição de número de carbonos dos experimentos e do diesel. A distribuição dos hidrocarbonetos com $\mathrm{C}_{4}-\mathrm{C}_{10}, \mathrm{C}_{11}, \mathrm{C}_{13}, \mathrm{C}_{18}, \mathrm{C}_{26}$ dos experimentos é similar ao diesel. Os percentuais de hidrocarbonetos com $\mathrm{C}_{15}, \mathrm{C}_{16}$, $\mathrm{C}_{17}, \mathrm{C}_{22}$ e $\mathrm{C}_{25}$, das fases pesadas dos experimentos, são maiores se comparados com os percentuais destas moléculas no diesel.

Na Tabela 2 estão descritas as propriedades do óleo derivado do 
a)

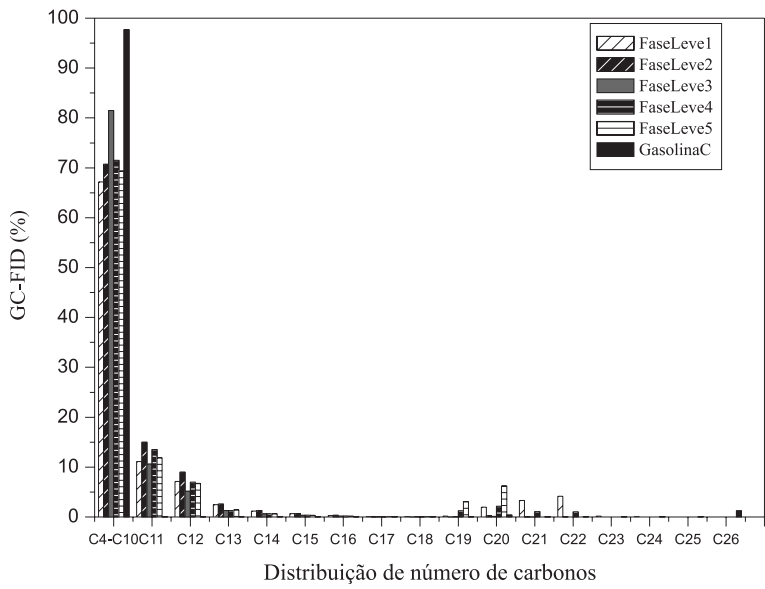

b)

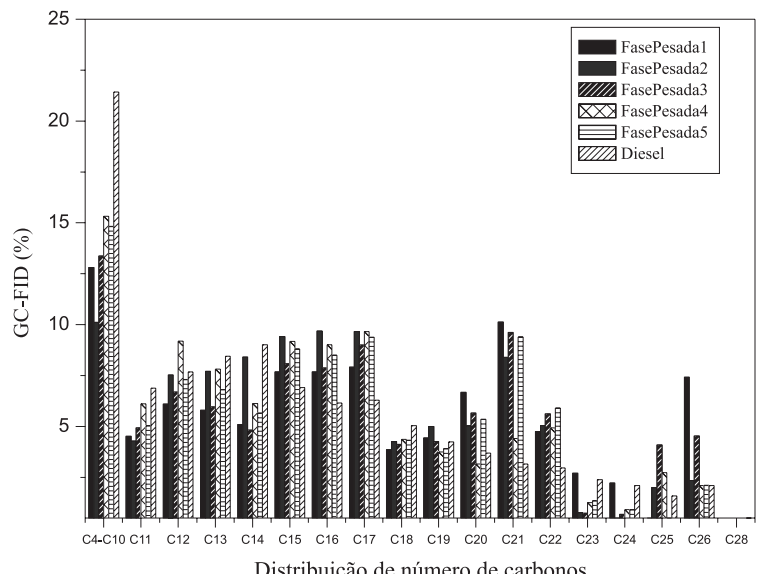

Figura 3. Distribuição de número de carbonos da fase leve e gasolina C (a) e fase pesada e diesel (b) dos Experimentos 1, 2, 3, 4 e 5

craqueamento, leve e pesado, para os experimentos realizados com a mistura de lodo de estamparia têxtil e óleo de fritura usado e para o experimento realizado sem o lodo, denominado branco. A densidade relativa do óleo diesel e da gasolina $\mathrm{C}$ foi também avaliada, utilizando o mesmo procedimento experimental. Os resultados aferidos foram de 0,850 $\pm 0,04$ para o óleo diesel e 0,715 $\pm 0,02$ para a gasolina $C$. Comparando estes resultados com os da Tabela 2, observa-se a similaridade numérica da densidade relativa do diesel quando comparado com a fase pesada dos experimentos realizados.

Tabela 2. Propriedades das frações leve e pesada do óleo

\begin{tabular}{cccc}
\hline Fração do óleo & Experimento & Densidade $\left(\mathrm{g} \mathrm{cm}^{-3}\right)$ & $\begin{array}{c}\text { Índice de acidez } \\
\left(\mathrm{mg} \mathrm{KOH} \mathrm{g}^{-1}\right)\end{array}$ \\
\hline leve & 1 & $0,795 \pm 0,01$ & $26,77 \pm 0,68$ \\
leve & 2 & $0,796 \pm 0,03$ & $12,79 \pm 0,00$ \\
leve & 3 & $0,779 \pm 0,08$ & $22,62 \pm 0,16$ \\
leve & 4 & $0,798 \pm 0,03$ & $27,68 \pm 0,32$ \\
leve & 5 & $0,782 \pm 0,12$ & $14,68 \pm 0,02$ \\
leve & branco & $0,730 \pm 4,99$ & $46,12 \pm 0,74$ \\
pesada & 1 & $0,855 \pm 0,02$ & $25,44 \pm 0,50$ \\
pesada & 2 & $0,858 \pm 0,01$ & $12,43 \pm 0,16$ \\
pesada & 3 & $0,860 \pm 0,15$ & $30,79 \pm 0,02$ \\
pesada & 4 & $0,851 \pm 0,18$ & $23,55 \pm 0,15$ \\
pesada & 5 & $0,852 \pm 0,25$ & $23,19 \pm 2,68$ \\
pesada & branco & $767,9 \pm 10,04$ & $41,08 \pm 3,64$ \\
\hline
\end{tabular}

Percebe-se, na Tabela 2, que as frações do experimento 2 contêm menores índices de acidez, tanto para a fase leve quanto para a fase pesada. Os índices de acidez situaram-se na faixa de 12,43 $\pm 0,16$ a 30,79 $\pm 0,02 \mathrm{mg} \mathrm{KOH} \mathrm{g}^{-1}$. Os dados acima, se comparados com os resultados obtidos por outros autores, ${ }^{17}$ que utilizaram procedimentos experimentais semelhantes e obtiveram índices de acidez do óleo leve na ordem de 131,2 mg KOH g ${ }^{-1}$ e óleo pesado com 107,3 mg KOH g ${ }^{-1}$, mostram o impacto do uso do lodo de estamparia na qualidade dos produtos obtidos. Os índices de acidez dos óleos derivados do craqueamento térmico de óleo vegetal de soja, palma e mamona foram 116,2, 133,3 e 207,5 mg KOH $\mathrm{g}^{-1}$, respectivamente. ${ }^{25}$ Os valores de índice de acidez do óleo leve obtido por craqueamento térmico apresentados na literatura mostram valores da ordem de seis a dez vezes maiores do que os obtidos na melhor condição de operação deste trabalho (experimento 2) e de três a cinco vezes para a pior condição deste trabalho (experimento 4). Da mesma forma, para o óleo pesado, os valores são da ordem de três a nove vezes maiores que os da literatura para óleos derivados do craqueamento térmico de óleos vegetais. Por comparação dos índices de acidez dos experimentos de craqueamento de óleo de fritura usado com e sem o lodo de estamparia têxtil (Tabela 2) percebe-se redução significativa no índice de acidez, de $46,12 \pm 0,71$ para $12,79 \pm 0,00$ para a fase leve, e de 41,04 $\pm 3,64$ para $12,43 \pm 0,16$ para a fase pesada.

\section{CONCLUSÕES}

A realização do craqueamento termo-catalítico utilizando a mistura dos resíduos resultou na obtenção de produtos sólidos, líquidos e gasosos. Os produtos líquidos obtidos foram analisados e identificados como compostos distribuídos entre $\mathrm{C}_{4}$ e $\mathrm{C}_{22}$. As curvas de destilação identificam compostos distribuídos por faixa de temperatura de ebulição, similares ao diesel. Os produtos do craqueamento foram purificados por destilação simples com cortes que resultaram na obtenção de frações de óleo leve $\left(30-180^{\circ} \mathrm{C}\right.$ ) e óleo pesado (acima de $180{ }^{\circ} \mathrm{C}$ ). Os resultados da caracterização destes mostram que a densidade relativa da fase pesada situa-se na faixa paramétrica do diesel. A análise dos índices de acidez mostra que este parâmetro é menor se comparado com os dados da literatura e ao experimento realizado sem o lodo, o branco, devido, essencialmente, à ação catalítica do lodo de estamparia têxtil. A análise cromatográfica mostra a presença de hidrocarbonetos na faixa de $\mathrm{C}_{4}-\mathrm{C}_{10}$, inferiores à gasolina $\mathrm{C}$, o que demanda melhorias nos procedimentos de destilação fracionada ou de cortes. A análise estatística dos experimentos possibilitou identificar o tempo de residência como o fator de maior influência no rendimento da fase orgânica dos experimentos de craqueamento termo-catalítico. Dos experimentos realizados, o maior rendimento em óleo foi o do experimento 3 , que apresentou maiores concentrações das frações leves e pesadas, com maior massa de hidrocarbonetos na faixa de $\mathrm{C}_{4}$ a $\mathrm{C}_{10}$. Este fato confirma o efeito catalítico de compostos inorgânicos presentes no lodo de estamparia, que reduz a temperatura ótima de craqueamento observada em trabalhos anteriores, de $500-525^{\circ} \mathrm{C}$ para $475^{\circ} \mathrm{C}$ reduzindo, também, o índice de acidez do óleo. De forma geral, pode-se concluir que os procedimentos metodológicos descritos neste trabalho apresentam a viabilidade do uso do processo de craqueamento termo-catalítico para a produção de biocombustíveis com potencial para substituírem os combustíveis fósseis e como estratégia para a destinação final de resíduos de óleo de fritura usado e do lodo de estamparia têxtil.

\section{AGRADECIMENTOS}

Ao MCT/FINEP/CNPQ, Convênio GENEPETRO, MCT/FINEP/ CNPQ/SEBRAE, Convênio Pirólise de resíduos, às empresas têxteis representadas pela AMPE-Blumemau, pelo apoio financeiro que tornou possível a execução deste trabalho. 


\section{REFERÊNCIAS}

1. Suarez, P. A. Z.; Moser, B. R.; Sharma, B. K.; Erhan, S. Z.; Fuel 2009, $88,1143$.

2. Bellaver, C.; Zanotto, D. L.; Conferência APINCO, Santos, Brasil, 2004.

3. Patil, P.; Deng, S.; Rhodes, I. J.; Lammers, P. J.; Fuel 2010, 89, 360.

4. Lam, M. K.; Lee, K. T.; Mohamed, A. R.; Biotechnol. Advances 2010, 28,500 .

5. Bridgwater, T.; J. Sci. Food Agric. 2006, 86, 1755.

6. Bhuah, W. K.; Cunliffe, A. M.; Williams, P. T.; Process Saf. Environ. Prot. 2007, 85, 450 .

7. Oliveira, M. L.; Cabral, L. L.; Leite, M. C. A. M.; Marques, M. R. C.; Polímeros 2009, 19, 3379.

8. Ucar, S.; Ozkan, R. A.; Bioresour. Technol. 2008, 99, 8771.

9. Fytili, D.; Zabaniotou, A.; Renew. Sust. Energ. Rev. 2008, 12, 116.

10. Hwang, I. H.; Ouchi, Y.; Matsuto, T.; Chemosphere 2007, 68, 1913.

11. Kim, Y.; Parker, W.; Bioresour. Technol. 2008, 99, 1409.

12. Mocelin, C.; Dissertação de Mestrado, Universidade Tecnológica Federal do Paraná, Brasil, 2007.

13. Rulkens, W.; Energy Fuels 2008, 22, 9.

14. Thipkunthod, P.; Meeyoo, V.; Rangsunvigit, P.; Rirksomboon, T.; J. Anal. Appl. Pyrolysis 2007, 79, 78.

15. Tsai, W.; Chang, J.; Hsien, K.; Chang Y.; Bioresour. Technol. 2009, 100, 406.

16. Maher, K. D.; Bressler, D. C.; Bioresour. Technol. 2007, 98, 2351.

17. Wiggers, V. R.; Wisniewski, A. J.; Madureira, L. A. S.; Barros, A. A. C.; Meier, H. F.; Fuel 2009, 88, 2135.

18. Wiggers, V. R.; Meier, H. F.; Wisniewski, A. J.; Barros, A. A. C.; Maciel, M. R. W.; Bioresour. Technol. 2009, 100, 6570.

19. Wisniewski, A. J.; Wiggers, V. R.; Simionato, E. L.; Meier, H. F.; Barros, A. A. C.; Madureira, L. A. S.; Fuel 2010, 89, 563.

20. Miranda, R.; Sosa, C.; Martínez, D.; Vasile, C.; J. Anal. Appl. Pyrolysis 2007, 80, 489

21. Muniz, L. A. R.; Costa, A. R.; Steffani, E.; Zattera, A. J.; Hofsetz, K.; Bossardi, K.; Valentini, L.; Braz. J. Chem. Eng. 2003, 20, 63.
22. Suarez, P. A. Z.; Meneghetti, S. M. P.; Meneghetti, M. R.; Wolf, C. R.; Quim. Nova 2007, 30, 667.

23. Blin, J.; Volle, G.; Girard, P.; Bridgwater, T.; Meier, D.; Fuel 2007, 86, 2679.

24. Chang, C.; Wan, S.; Ind. Eng. Chem. 1947, 39, 1543.

25. Lima, D. G.; Soares, V. C. D.; Ribeiro, E. B.; Carvalho, D. A.; Cardoso, E. C. V.; Rassi, F. C.; Mundim, K. C.; Rubim, J. C.; Suarez, P. A. Z.; J. Anal. Appl. Pyrolysis 2004, 71, 987.

26. Junming, X.; Jianchun, J.; Jie, C.; Yunjuan, S.; Bioresour. Technol. 2010, $101,5586$.

27. ABNT - Associação Brasileira de Normas Técnicas; Determinação do teor de sólidos totais, totais fixos e totais voláteis, NBR-14363, Rio de Janeiro, 1999.

28. ABNT - Associação Brasileira de Normas Técnicas; Determinação de perda por calcinação, NBR-9382, Rio de Janeiro, 1986.

29. ABNT - Associação Brasileira de Normas Técnicas; Preparação para ensaios de compactação e ensaios de caracterização, NBR-6457, Rio de Janeiro, 1986.

30. ABNT - Associação Brasileira de Normas Técnicas; Destilação à pressão atmosférica, NBR-9619, Rio de Janeiro, 2005.

31. Guedes, C. L. B.; Adão, D. C.; Quessada, T. P.; Borsato, D.; Galão, O. F.; Mauro, E. D.; Pérez, J. M. M.; Rocha, J. D.; Quim. Nova 2010, 33, 781.

32. ABNT - Associação Brasileira de Normas Técnicas; Determinação da massa específica, densidade relativa $e^{\circ} A P I$, NBR-7148, Rio de Janeiro, 2006.

33. American Society for Testing Materials; Standard D 974 Standard Test Method for Acid and Base Number by Color-Indicator Titration, 2008.

34. Arpa, O.; Yumrutas, R.; Demirbas, A.; Appl. Energy 2010, 87, 122.

35. Wiedemann, L. S. M.; D'avila, L. A.; Azevedo, D. A.; J. Braz. Chem. Soc. 2005, 16, 139.

36. Pescarini, M. H.; Barros, A. A. C.; Maciel, M. R. W.; Comput. Chem. Eng. 1996, 1, 279.

37. Murugan, S.; Ramaswamy, M. C.; Nagarajan, G.; Fuel Process. Technol. 2009, 90,67 . 